\title{
Epilepsy after missile wounds of the head
}

\author{
ADELOLA ADELOYE AND E. LATUNDE ODEKU
}

From the Neurosurgery Unit, Department of Surgery, University of Ibadan, Ibadan, Nigeria

SUMMARY Two hundred and thirty-seven Nigerians with missile head injury were treated at the University College Hospital (UCH) Ibadan, between July 1964 and January 1970. Among the 165 of these patients who have been followed up for over a year, the incidence of epilepsy has been $11.4 \%, 18.75 \%$, and $33.3 \%$ in a follow-up period ranging between one to two years, two to three years, and three to five years respectively.

Wounds in the parietal region, especially those at the vertex, were followed by epilepsy more frequently than injuries elsewhere on the head. Of these wounds, tangential skull injuries and through-and-through brain injuries were more epileptogenic than others.

Fits which occurred within a fortnight of wounding have been designated as 'early' fits, and they appeared to differ in their aetiology from 'late' fits.

The phenomenon of epilepsy occurring after injuries to the head must have been observed in the prehistoric era when man first clubbed man, but the earliest documented reference to the problem of post-traumatic epilepsy is credited by common consent to Hippocrates. He recorded right-sided convulsive seizures which followed injury to the left cerebral hemisphere, a contribution which kindled interest in the surgical aspects of traumatic epilepsy on which a vast amount of literature had accumulated by the middle of the sixteenth century (Davis, 1953). In later years, the wars in America, Europe, and Korea provided material for the study of epilepsy after missile wounds of the head. The type of injuries studied, the period after wounding selected for these studies, and the duration of observation varied from series to series so that the frequency of post-traumatic epilepsy in missile head wounds had been variously estimated by different observers. It was recorded at $13.7 \%$ during the American Civil War and at $4.3 \%$ during the FrancoPrussian war (Turner, 1923). Among the British soldiers with missile wounds of the head during the first world war, Sargent (1921) reported an incidence of $4.5 \%$, Rawling (1922) $25 \%$, Wagstaffe (1928) $9 \cdot 8 \%$, Stevenson (1931) $1.5 \%$, Ascroft (1941) $34 \%$, Denny-Brown (1942) 8.4\%; and Credner (1930) documented an incidence of $38 \%$ among Germans with war head injuries. In a five-year follow-up of 820 brain-wounded patients from the second world war, Russell and Whitty (1952) found that $43 \%$ had epileptic seizures; in another series of 286 patients Watson (1952) observed that $36 \%$ and $41.6 \%$ had epilepsy within two and three years of? wounding respectively, and Walker and Jablonœ (1959) recorded an incidence of $28 \%$ among United $\mathbb{Q}$ States soldiers with military head injuries. More recently still, Caveness (1963) recorded epilepsy ino $42 \%$ of 197 veterans of the Korean war with missile head wounds who were followed up for eight to 11 years.

The 30 months of civil war in Nigeria provided us with most of the material for a study of the pattern of traumatic epilepsy after missile wounds of the head. Among the soldiers who formed the bulk of the patients, referral from the base hospitals close to the war front to University College Hospital, Ibadan, was considered in the acute stage of wounding if the patient could survive the journey from the war front to Ibadan; in those with seemingly minor wounds, it was in most cases the appearance of neurological disturbances that brought them here. These considerations have unavoidably imposed an element of selection on our material. We have, however, included in the series all consecutive admissions into UCH, Ibadan, for missile wounds of the head, so that it has been possible to have a glimpse of the pattern of occurrence of epilepsy both in the immediate and later period after wounding.

\section{PATIENTS}

There were 237 Nigerians seen at the Neurosurgery Clinic of UCH, Ibadan, between July 1964 and 
January 1970 with missile wounds of the head. Only three civilians were admitted before the beginning of the civil war in July 1967 (Table 1). With the exception of three females injured in combat zones during the civil war all the patients were males. Fifteen of the patients were civilians, and the rest were soldiers-young adult males who were practically homogeneous with reference to their ages. These patients were referred to the Neurosurgery Unit of this hospital either from other civilian or military hospitals, or from the Army medical reception stations close to the war fronts.

TABLE 1

DISTRIBUTION OF PATIENTS

\begin{tabular}{lccc}
\hline \multicolumn{1}{c}{ Period of time } & $\begin{array}{c}\text { Total patients } \\
\text { (no.) }\end{array}$ & \multicolumn{2}{c}{ Follow-up (no.) } \\
\cline { 3 - 4 } & & $\begin{array}{c}\text { less than } \\
\text { I yr }\end{array}$ & over 1 yr \\
& & - & 3 \\
July 1964-June 1967 & 3 & 7 & 48 \\
July 1967-June 1968 & 55 & 13 & 114 \\
July 1968-June 1969 & 127 & 52 & - \\
July 1969-January 1970 & 52 & 72 & 165 \\
\hline Total & 237 & &
\end{tabular}

The diagnosis of post-traumatic epilepsy has been made entirely on clinical grounds, and so far electroencephalographic studies have not been included in the assessment. Patients who complained of 'their eyes turning' only, feeling dizzy, or of shivering attacks were excluded. In every instance, a past or family history of epilepsy was sought.

\section{OBSERVATIONS}

DELAY The average duration of time which elapsed between wounding and arrival at this hospital was 10 days for all the patients.

DISTRIBUTION Table 1 shows the distribution of the 237 patients over the period covered by this series. Excluding those who were wounded in and after July 1969 , practically all those who have been followed up for less than a year were the patients who died within a year of wounding. In all 165 patients have been followed up for more than one year.

INCIDENCE OF POST-TRAUMATIC EPILEPSY Thirty-five of the patients had post-traumatic fits. They were all soldiers, except four civilians. All were male patients, except a civilian female of 16 years. The youngest and the oldest patients were 4 and 40 years respectively and both were civilians. The average age for the group was 23.4 years. None had a personal past history of epilepsy, nor a family history.

Nine of these 35 patients died within a year of wounding. Three others have been followed up for only six months. Table 2 shows the percentage incidence of epilepsy in the remaining 23 patients who have been followed up for more than a year. It is seen that the longer the duration of the followup period, the higher the incidence of epilepsy.

TABLE 2

INCIDENCE OF EPILEPSY

\begin{tabular}{cccc}
\hline $\begin{array}{c}\text { Duration of follow-up } \\
(y r)\end{array}$ & $\begin{array}{c}\text { Total patients } \\
(\text { no. })\end{array}$ & $\begin{array}{c}\text { With epilepsy } \\
(\text { no. })\end{array}$ & $\begin{array}{c}\text { Incidence } \\
(\%)\end{array}$ \\
\hline $1-2$ & 114 & 13 & $11 \cdot 4$ \\
$2-3$ & 48 & 9 & $18 \cdot 75$ \\
$3-5$ & 3 & 1 & $33 \cdot 3$ \\
\hline-165 & 23 \\
\hline
\end{tabular}

MISSILE TYPE The various types of missiles encountered in this series were the heavy, conical bullets from rifles and machine guns deployed in the war exercises; small rounded bullets from dane-guns used in civilian injuries, and metallic fragments dispersed from exploded mines, mortar bombs, and hand grenades. Twenty-three of the wounds were inflicted by bullets and 11 by metallic fragments. In one case, the missile type was unknown.

SITE OF Wounding Table 3 shows the relative frequency of involvement of the various anatomical areas and the incidence of epilepsy in each. In penetrating wounds caused by metallic fragments, there were in some cases multiple involvement of anatomical areas of the head. In tangential skull wounds with through-and-through scalp lesions, and in the through-and-through brain wounds, the anatomical sites of the entry and exit wounds have been incorporated, since in our experience the brain damage at the exit wounds has generally been considerable. Hence, in Table 3 the recorded total number of sites of wounding and also the occurrence of epilepsy exceeded the number of patients. Wounds of the

TABLE 3

SITE OF WOUNDING AND INCIDENCE OF EPILEPSY

\begin{tabular}{lccc}
\hline \multicolumn{1}{c}{ Anatomical site } & Total (no.) & With epilepsy (no.) & Incidence (\%) \\
\hline Frontal & 81 & 9 & $11 \cdot 1$ \\
Parietal & 94 & 23 & 24.5 \\
Temporal & 31 & 4 & 12.9 \\
Occipital & 36 & 3 & 8.3 \\
Vertex & 7 & 2 & 28.6 \\
\hline
\end{tabular}


parietal area were more frequent than those of other areas, and the incidence of post-traumatic epilepsy was highest after these parietal wounds especially those at the vertex.

TYPES OF WOUNDS Table 4 shows the incidence of epilepsy in the different categories of head wounds encountered. We were unable to include in one of our defined categories the wounds of those patients who were referred to $\mathrm{UCH}$ after an initial operative treatment during which the integrity of the missile wound had been altered.

TABLE 4

TYPES OF HEAD WOUND AND INCIDENCE OF EPILEPSY

\begin{tabular}{lccc}
\hline \multicolumn{1}{c}{ Type of wound } & $\begin{array}{c}\text { Total } \\
\text { (no.) }\end{array}$ & $\begin{array}{c}\text { With epilepsy } \\
\text { (no.) }\end{array}$ & $\begin{array}{c}\text { Incidence } \\
(\%)\end{array}$ \\
\hline Scalp alone & 25 & 2 & 8 \\
Tangential skull wound & 85 & 17 & 20 \\
Penetrating brain wound & 100 & 12 & 12 \\
Through-and-through brain wound & 15 & 3 & 20 \\
Unspecified & 12 & 1 & $8 \cdot 3$ \\
\hline Total & 237 & 35 & $14 \cdot 8$ \\
\hline
\end{tabular}

Through-and-through brain wounds with their capacity to cause severe brain damage especially at the exit wound, and tangential skull wounds with their tendency to cause damage to relatively extensive areas of the cortex by in-driven bone fragments, were more epileptogenic than the other wounds.

TIME OF ONSET OF FIRST FIT AFTER WOUNDING This is illustrated graphically in Fig. 1 . Ten $(28.6 \%)$ of the 35 patients had their first fit within the first fortnight after wounding, with $90 \%$ of them occurring in the first week. From the fourth to eighth week after injury, there was a more or less even distribution; the number of affected patients became greater from the third month after wounding to a year, after which there was a fall in the incidence of fits.

In the group where epilepsy started within the

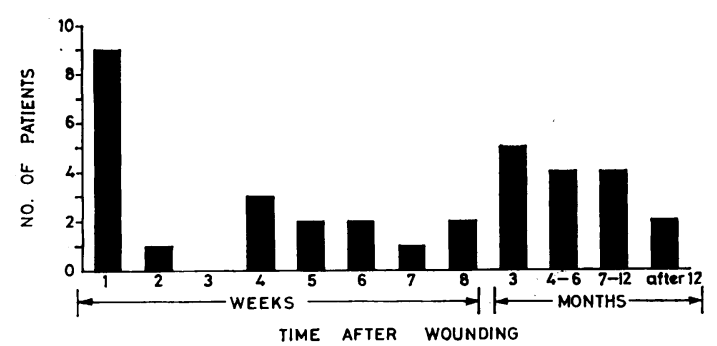

FIG. 1. Time of first fits in missile head wounds.

first two weeks of injury, six had generalized seizures and four, focal attacks. The generalized fits were associated with severe wounds. The three patients in this category who died within one to three days of injury all had generalized fits. Only one patient had recurrent fits which recurred after operation and which persisted for months afterwards. The 'early' fits probably occurred as a result of the primary anatomical derangement and its immediate consequences. In those who had their first fits between four to eight weeks after wounding, infection was an important cause (Table 5). It supervened when the dura mater had been lacerated especially with the long time-interval between wounding and hospitalization. The infection in this group had a bad prognosis. In others whose fits commenced three to 12 months after their head injury, the probable cause was a combination of infection and gliosis, both of which could be provoked by retained bone and metallic fragments. At operation in one patient in this category, pockets of cerebral abscess were found around bone fragments which had been retained intracranially. Epilepsy occurring for the first time a year after wounding in the absence of overt infection is probably due to secondary anatomical derangement, in the nature of meningocerebral cicatrix.

TABLE 5

TIME OF FIRST FIT

\begin{tabular}{|c|c|c|c|c|c|}
\hline Time & Number & Operative findings & Infection & Mortality & Probable cause of fit \\
\hline $1 \mathrm{st}$ wk & 9 & & - & 3 & \\
\hline 2nd wk & 1 & & - & - & Primary anatomical derangement \\
\hline 3rd wk & - & & - & - & \\
\hline 4th wk & 3 & & 2 & 2 & \\
\hline 5 th wk & 2 & & 2 & 1 & Infection predominantly \\
\hline 6 th wk & 2 & Dura intact & - & - & \\
\hline 7 th wk & 1 & Dura intact & - & - & \\
\hline 8 th wk & 2 & Retained metallic fragment (1) & 一 & - & \\
\hline 3rd mth & 5 & Retained metallic fragment (2) & 2 & 2 & \\
\hline 4th-6th mth & 4 & Ventricle penetrated (2) & $\overline{3}$ & $\overline{1}$ & Infection, gliosis \\
\hline 7 th mth-1 yr & 4 & Retained metallic and bone fragment (1) & 1 & - & \\
\hline After 1 yr & 2 & & - & - & Gliosis predominantly \\
\hline
\end{tabular}


Of the 30 patients who had operation, nine $(30 \%)$ had fits in the immediate post-operative period, which varied from two hours to 10 days.

TYPES OF FITS OBSERVED AND THEIR SIGNIFICANCE There were 16 examples of focal motor fits, 10 of generalized seizures, and five of focal fits becoming generalized, with a mortality of $12.5 \%, 50 \%$, and $40 \%$ respectively. Generalized fits were commonly seen in the first fortnight of wounding when they were associated with severe anatomical damage, and again from four to eight weeks after wounding when they were associated with intracranial infections. Focal fits becoming generalized were particularly frequent in the presence of intracranial suppuration. In four patients, the nature of epileptic fits suffered was not clearly stated.

BEARING OF OPERATIVE FINDING ON INCIDENCE OF EPILEPSY In 196 cases in which information was available about the state of the dura mater, there was dural penetration in 142 cases, 27 (19\%) of whom had epilepsy; of the 54 with intact dura, only four $(7 \%)$ had epilepsy.

In most cases, small amounts of haematomata were encountered at all levels of the intracranial cavity along the missile path, so that, except on the rare occasion where the haematoma was massive, it was not easy to evaluate its significance.

Fourteen $(40 \%)$ of the 35 patients with epilepsy had bone fragments or both bone and metallic fragments driven intracranially into their brain substance, a situation which is universally believed to be associated with increased occurrence of traumatic epilepsy.

EFFECT OF ANTICONVULSANTS ON COURSE OF EPILEPSY Phenytoin and phenobarbitone were used prophylactically in every case of missile head wound for the first fortnight to three weeks, and then one or both drugs continued afterwards for at least six to 12 months in instances where the brain was penetrated.

In this series, anticonvulsants had little or no effect on the epilepsy which occurred within a week after operation. These post-operative cases were the ones which allowed such assessment to be made in this hospital where patients arrive on the average 10 days after wounding, during which time they have not had anticonvulsant therapy. It could safely be inferred that the fits which occur within a week of injury, and are due predominantly to cortical damage, may likewise be unresponsive to anticonvulsants.

These drugs had little or no effect on the course of those 'late' epilepsies where intracranial suppuration was dominant; in these cases, the fits terminally increased in frequency and duration. In the other 'late' fits which were presumably due to gliosis, these drugs helped to reduce the frequency of attacks; indeed, recurrences were often recorded at such times when these patients forgot to take their drugs or ran out of them.

Two patients who were treated with penicillin, streptomycin, and sulphadiazine, and the two anticonvulsant drugs, phenytoin and phenobarbitone, developed Stevens-Johnson syndrome while still on anticonvulsants but weeks after cessation of their anti-infective drugs (Adeloye, Alabi, Familusi, and Odeku, 1971). Both survived. In one patient the erythema multiforme recurred after re-administration of phenytoin.

MORTALITY There were nine deaths out of the 35 patients with post-traumatic epilepsy. All of the nine patients had wounds with dural penetration, with either severe anatomical damage or intracranial suppuration or both. The dura mater was lacerated in 28 of these 35 cases which placed the mortality in the presence of dural penetration at $32 \%$.

\section{DISCUSSION}

It is doubtful if we will ever know the true incidence of traumatic epilepsy after missile head wounds (Denny-Brown, 1944). Epilepsy can occur at any time from the immediate post-traumatic period to several years after injury, and its diagnosis has depended more on clinical impressions than on other methods in most series. Besides, since the sources from which the patients studied were drawn and the length of follow-up after wounding differed from series to series, it is hardly surprising that the statistical estimate of the frequency of epilepsy has been so variable. In the United Kingdom, for example, most of the cases of missile head injury during the first world war were drawn from the files of the British Ministry of Pensions (Sargent, 1921; Wagstaffe, 1928; Ascroft, 1941) and some were traced by circularizing (Rawling, 1922). Since medical boards must be convinced about the genuineness of epilepsy to make a victim of missile head wound pensionable, doubtful cases would not be included (Whitty, 1947). Wagstaffe (1928) excluded those who died shortly after wounding, and in his series the earliest fit was recorded two months after wounding. Ascroft's (1941) series was made up of 'four year cases', which excluded those who died within the first few years before their pension reached the stage of final award. Under those conditions, it was likely that the true incidence might have been different. The longer the duration of the follow-up period, the higher the incidence of 
epilepsy as exemplified by our series and that of Watson (1952). Indeed, Russell and Whitty (1952) who found an incidence of $43 \%$ after five years of follow-up predicted that a 10-year follow-up of the same series might yield a figure of about $50 \%$.

In our experience, bullet injuries are more likely to be followed by epilepsy than wounds from metallic fragments. This may be because a high proportion of tangential skull wounds was caused by bullets. These tangential skull wounds have a considerable tendency to involve relatively larger areas of the cortex than the penetrating brain wounds in which the missile often carves out deep tracks with relatively small cortical damage. The high incidence of fits in wounds of the parietal region in our series agreed with the observations of Credner (1930) and Russell and Whitty (1952).

The identity of 'early' and 'late' epilepsies has been established on a temporal basis in blunt head injuries in civilian practice by Jennett and Lewin (1960) and Jennett (1969) who suggested that 'early epilepsy' should be reserved for fits which occur in the first week after blunt injury and all fits occurring after that time should be classified as 'late' epilepsy. In missile head wounds, on the other hand, the identity of 'early' and 'late' fits has not been similarly established. Thus 'early epilepsy' has been variously accepted as epilepsy occurring within 12 to 24 hours of wounding (Elvidge, 1939), within the first few days after injury (Wagstaffe, 1928; Symonds, 1935) or within the first week (Ascroft, 1941). Hence Whitty (1947) admitted that the phrase 'early attacks' needed definition. Although the longest interval after wounding in which he recorded 'early attacks' was 11 days, he did not accord them a temporal definition as such. Instead he suggested that these fits occur 'when widespread delayed effects of injury are at a maximum' (Jennett, 1969). In our series, a considerable number of first fits were recorded in the first week after wounding, one in the second week and none in the third week (Fig. 1). In the missile series of Russell and Whitty (1952) of 73 patients (Jennett, 1969), 47 had their first fits in the first week, 10 in the second week, and none in the third week. These findings would suggest that the pathophysiological processes of 'early' epilepsy still continue to operate in the second week of wounding, and that 'early' epilepsy in missile head wounds ought to be defined as that which occurred during the first fortnight after wounding, as Caveness (1963) also suggested.

It would appear that 'early' and 'late' fits in missile head wounds are aetiologically different, as was first suggested by Sargent in 1921. Early fits occurred when 'brain oedema, local vascular change or actual brain debris were still present' (Whitty,
1947), and 'late' fits in this series were associated earlier on with intracranial infection and latterly they were due to progressive gliosis or a combination of infection and gliosis. All investigators have agreed that wound infection favours the onset of late fits, except Russell and Whitty (1952) who found it a relatively unimportant cause of late fits. It has been suggested that the presence of meningocerebral cicatrix may cause a late epilepsy (Penfield and Humphreys, 1940). Such gliosis, per se, cannot adequately explain the occurrence of traumatic epilepsy for which Russell (1947) postulated injury to 'suppressor areas' of the cerebral cortex.

The role of operative debridement of these wounds in the genesis of epilepsy has excited some speculative remarks. Thirty per cent of our patients who had debridement of their wounds had fits in the immediate post-operative period, which ranged from two hours to 10 days. Ascroft (1941) recorded epilepsy in $53 \%$ of cases where metallic fragments were removed from the brain and $38 \%$ when they were left in. It would appear from these figures alone that surgical interference per se could increase the tendency to suffer from post-traumatic epilepsy buto for the rider added by Ascroft (1941) that debride ment would be done in cases of superficially place fragments which in turn would have caused extensive cortical damage thus predisposing the patient to epilepsy.

\section{REFERENCES}

Adeloye, A., Alabi, G. O., Familusi, J. B., and Odeku, E. L (1971). Stevens-Johnson syndrome following anticonvulsant therapy in penetrating head injury. Ghana Medical Journal. (In press.)

Ascroft, P. B. (1941). Traumatic epilepsy after gunshot wounds of the head. Brit. med. J., 1, 739-744.

Caveness, W. F. (1963). Onset and cessation of fits following craniocerebral trauma. J. Neurosurg., 20, 570-583.

Credner, L. (1930). Klinische and soziale Auswirkungen von Hirnschädigungen. Z. ges. Neurol. Psychiat., 126, 721-757.

Davis, L. (1953). Principles of Neurological Surgery, page 485, 4th edition. Lea and Febiger: Philadelphia.

Denny-Brown, D. (1942). The sequelae of war head injuries. New Engl.J. Med., 227, 771-780 and 813-821.

Denny-Brown, D. (1944). The clinical aspects of traumatic epilepsy. Amer. J. Psychiat., 100, 585-592.

Elvidge, A. R. (1939). Remarks on post-traumatic convulsive state. Trans. Amer. neurolog. Assn., 65, 125-129. In Injuries of the Brain and Spinal Cord and their Coverings, edited by $\mathrm{S}$. Brock, page 259, 3rd edition. Baillière, Tindall and Cox: London.

Jennett, W. B. (1969). Early traumatic epilepsy. Definition and identity. Lancet, 1, 1023-1025.

Jennett, W. B., and Lewin, W. (1960). Traumatic epilepsy

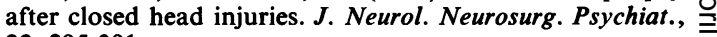
23, 295-301.

Penfield, W., and Humphreys, S. (1940). Epileptogenic lesions $\Omega$ of the brain. Arch. Neurol. Psychiat. (Chic.), 43, 240-261. N

Rawling, L. B. (1922). The remote effects of gunshot wounds of the head. Brit. J. Surg., 10, 93-126. 
Russell, W. R. (1947). The anatomy of traumatic epilepsy. Brain, 70, 225-233.

Russell, W. R., and Whitty, C. W. M. (1952). Studies in traumatic epilepsy. 1. Factors influencing the incidence of epilepsy after brain wounds.J. Neurol.Neurosurg. Psychiat., 15, 93-98.

Sargent, P. (1921). Some observations on epilepsy. Brain, 44, 312-328.

Stevenson, W. E. (1931). Epilepsy and gunshot wounds of the head. Brain, 54, 214-224.

Symonds, C. P. (1935). Traumatic epilepsy. Lancet, 2, 12171220.
Turner, W. A. (1923). Epilepsy and gunshot wounds of the head. J. Neurol. Psychopath., 3, 309-321.

Wagstaffe, W. W. (1928). The incidence of traumatic epilepsy after gunshot wounds of the head. Lancet, 2, 861-862.

Whitty, C. W. M. (1947). Early traumatic epilepsy. Brain, 70, 416-439.

Walker, A. E., and Jablon, S. (1959). A follow-up of headinjuried men of World War II. J. Neurosurg., 16, 600-609.

Watson, C. W. (1952). Incidence of epilepsy following craniocerebral injury. Arch. Neurol. Psychiat. (Chic.), 68, 831-834.

\section{The December 1970 Issue THE DECEMBER 1970 ISSUE CONTAINS THE FOLLOWING PAPERS}

Effect of intravenous sodium bicarbonate, disodium edetate $\left(\mathrm{Na}_{2}\right.$ EDTA), and hyperventilation on visual and oculomotor signs in multiple sclerosis FLOYD A. DAVIS, FRANK O. BECKER, JOEL A. MICHAEL, and ERIC SORENSEN

Relationship between volume flow and velocity in the cerebral circulation J. O. ROWAN, A. M. HARPER, J. D. MILLER, G. M. TEDESCHI, and W. B. JENNETT

Limitations of circulation time in the diagnosis of intracranial disease J. O. ROWAN, J. N. CROSS, G. M. TEDESCHI, and W. B. JENNETT

Effects of hyperbaric oxygen on intracranial pressure and cerebral blood flow in experimental cerebral oedema J. D. MILLER. I. McA. LEDINGHAM, and W. B. JENNETT

Regional cerebrovascular responses to acute ischaemia in normocapnia and hypercapnia: an experimental study in baboons LINDSAY SYMON

Extraneural metastases in ependymoma of the cauda equina LUCIEN J. RUBINSTEIN and WILLIAM J. LOGAN

Clinical spectrum of ocular bobbing JOHN O. SUSAC, WILLIAM F. HOYT, ROBERT B. DAROFF, and WILLIAM LAWRENCE

Effect of speed of muscle contraction on physiological tremor in normal subjects and in patients with thyrotoxicosis and myxoedema C. D. MARSDEN, J. C. MEADOWS, and G. W. LANGE

In vitro staining of intramuscular nerve endings $\mathbf{R} . \mathbf{H}$. EVANS, J. HAYNES, C. J. MORRIS, and A. L. WOOLF

Flexor reflex afferent nerve fibres in man BHAGWAN SHAHANI

The human blink reflex BHAGWAN SHAHANI
Acid maltase levels in muscle in heterozygous acid maltase deficiency and in non-weak and neuromuscular disease controls ANDREW G. ENGEL and MANUEL $R$. GOMEZ

The effect of acrylamide on the peripheral nervous system of the baboon ANTHONY HOPKINS

Refsum's syndrome: report of three cases C. D. QUINLAN and E. A. MARTIN

Malignant change in an intraspinal nerve sheath tumour D. J. B. ASHLEY and P. J. E. WILSON

Recurrent multiple cranial nerve palsies: a distinctive syndrome of cranial polyneuropathy JOHN C. STEELE and ARAMASI VASUVAT

Spinal perineurial and meningeal cysts I. M. TARLOV

Syndrome of absent abdominal muscles: two cases with microcephaly, polymicrogyria, and cerebellar malformations REID R. HEFFNER

Phenolic acid concentrations in the lumbar cerebrospinal fluid of Parkinsonian patients treated with L-dopa I. A. PUllar, JUNe M. Weddell, R. AHMED, and F. J. GILLINGHAM

Stereotaxic amygdalotomy and basofrontal tractotomy in psychotics with aggressive behaviour $K$. VARNET and ANNA MADSEN

Cerebral candidiasis: case report of brain abscess secondary to Candida albicans and review of literature JOSEPH T. BLACK

Familial occurrence of cavernous angiomata of the brain J. V. CLARK

Motor neurone disease and exposure to lead A. M. o. CAMPBELL, E. R. WILLIAMS, and D. BARLTROP

Book reviews

Copies are still available from the PUBLISHING MANAGER

BRITISH MEDICAL ASSOCIATION, TAVISTOCK SQUARE, LONDON, WC1H 9JR, price $£ 1 \cdot 50$ 